\title{
Targeted Krüppel-Like Factor 4 Gene Knock-Out in Retinal Ganglion Cells Improves Visual Function in Multiple Sclerosis Mouse Model
}

\author{
ㄴ) Venu Talla and Rajeshwari Koilkonda
}

https://doi.org/10.1523/ENEURO.0320-19.2020

Bascom Palmer Eye Institute, Department of Ophthalmology, University of Miami, Miller School of Medicine, Miami, FL 33136

\begin{abstract}
Axonal demyelination injury and neuronal degeneration are the primary causes of visual disability in multiple sclerosis (MS)-linked optic neuritis patients. Immunomodulatory therapies targeting inflammation have failed to avert the disease progression and no therapies exist to prevent the neuronal deficits seen in MS to date. Neuroprotective strategies targeting oligodendrocytes and astroglia have shown limited success due to a lack of axonal regeneration from injured neurons. In this study, we used the chronic experimental autoimmune encephalomyelitis (EAE) mouse model of MS to investigate the axonal regenerative approach to improve the neuronal function. Our approach focused on targeted knock-out (KO) of the developmentally regulated axon growth inhibitory Krüppel-like factor 4 (KIf4) gene in retinal ganglion cells (RGCs) of KIf4 ${ }^{\text {Ilffl }}$ mice by intravitreal delivery of AAV2-Cre-ires-EGFP recombinant virus (1) at the time of EAE sensitization and (2) after the onset of optic neuritis-mediated visual defects in the mice. KIf4 gene KO performed simultaneous with EAE sensitization prevented the visual loss as assessed by pattern electroretinograms (PERGs) in the mice and protected the RGCs from EAE-mediated death. More importantly, however, Klf4 gene KO after the onset of optic neuritis also resulted in RGC neuroprotection with additional restoration of their function, thereby improving the visual function outcomes in the EAE model. This study establishes the efficacy of Klf4 targeted knock-down in EAE even after the onset of disease symptoms, and thus should be further explored as a potential treatment strategy for MS/optic neuritis patients.
\end{abstract}

Key words: axon regeneration; demyelination; EAE; MS; neuroprotection; optic neuritis

\section{Significance Statement}

Multiple sclerosis (MS) is a leading cause of permanent disability in young adults in which effective treatment has remained elusive. The neuroprotective strategies targeting oligodendrocytes and astroglia have shown limited success due to a lack of axonal regeneration from injured neurons. In the current study, we explored the axon regenerative approach to treat MS in mouse model and showed that targeted knock-out (KO) of axon growth inhibitory Krüppel-like factor 4 (Klf4) gene in RGCs of experimental autoimmune encephalomyelitis (EAE) mice is efficient in preventing not only the EAE-mediated RGC death but also restoring the function of injured axons by facilitating regeneration, and thereby improving the visual function in the mice even after the onset of EAE-mediated visual defects.

Received August 10, 2019; accepted February 20, 2020; First published March $12,2020$.

The authors declare no competing financial interests.
Author contributions: V.T. designed research; V.T. and R.K. performed research; V.T. contributed unpublished reagents/analytic tools; V.T. and R.K. analyzed data; V.T. wrote the paper. 


\section{Introduction}

Multiple sclerosis (MS) is a chronic inflammatory and neurodegenerative disease of the central nervous system affecting over 0.7-0.9 million people with an estimated 10 -year cumulative prevalence of 309.2 per 100,000 adults in the United States (Adelman et al., 2013; Wallin et al., 2019). Experimental autoimmune encephalomyelitis (EAE), induced on administration of central nervous system (CNS) myelin components is one of the most widely used animal models for human MS (Guy and Rao, 1984; Kornek et al., 2000; Owens, 2003). MS/EAE is an inflammatory autoimmune disease characterized by inflammation, demyelination and progressive axonal loss in the CNS, which ultimately leads to permanent disability (Bjartmar and Trapp, 2001). Optic neuritis is one of the most common clinical manifestations of MS and is diagnosed as the initial symptom in $\sim 25 \%$ of MS patients, while $70 \%$ develop the condition during the course of the disease (Talman et al., 2010; Balcer et al., 2015). Since neurologic deficits of retinal ganglion cell (RGC)/optic nerve $(\mathrm{ON})$ injury are detected early during the onset of the disease and are more clinically apparent than elsewhere in the CNS, optic neuritis is instrumental for testing neuroprotective approaches for MS therapies and has been used in multiple clinical trials (Aktas et al., 2016).

To date, no effective therapy exists to prevent neuronal deficits associated with MS/optic neuritis, except for recent reports claiming prevention of neurologic deficits in an MS mouse model on intranasal delivery of the biological secretome of amnion-derived multipotent progenitor cells (Khan et al., 2017, 2019; Grinblat et al., 2018). Most of the initial MS research is focused on immunomodulatory therapies targeting the inflammatory and autoimmune components (Noseworthy et al., 2001). However, immunomodulatory drugs have thus far failed to prevent permanent disability in progressive MS due to a lack of axonal regeneration (Polman et al., 2006; Shirani et al., 2012). More recent efforts targeted the early onset axonal and neuronal degenerations, which are linked to disease progression in MS patients and are currently recognized as the primary cause of visual and neurologic disability in MS and optic neuritis patients (Trapp et al., 1998; Lovas et al., 2000; Kuhlmann et al., 2002; Bjartmar et al., 2003; Kutzelnigg et al., 2005). Consequently, research findings

This work was partially supported by an unrestricted grant to Bascom Palmer Eye Institute from Research to Prevent Blindness, National Institutes of Health Core Grant P30 EY014801.

Acknowledgements: We thank Dr. John Guy for his expert advice on experimental optic neuritis animal model; Dr. Vittorio Porciatti for his advice on PERG experiments; Dr. William W. Hauswirth's lab for assistance with AAV viral packaging; Dr. Valery I. Shestopalov and Dr. Sanjoy K. Bhattacharya for the critical comments on this manuscript; and Dr. Daniel Pelaez for the language editing of this manuscript. We also thank Dr. Jeffrey Goldberg for the kind gift of KIf4 ${ }^{\text {fl/fl }}$ mice and MMRRC-MO for providing heterozygous Klf4 floxed mice breeding pairs.

Correspondence should be addressed to Venu Talla at vtalla@miami.edu.

https://doi.org/10.1523/ENEURO.0320-19.2020

Copyright (C) 2020 Talla and Koilkonda

This is an open-access article distributed under the terms of the Creative Commons Attribution 4.0 International license, which permits unrestricted use, distribution and reproduction in any medium provided that the original work is properly attributed. on axonal protection/regeneration in MS/EAE helped to refocus therapeutic strategies to protect axons and their functions, particularly via enhanced regeneration (Bjartmar and Trapp, 2001; Bjartmar et al., 2003).

In contrast to embryonic or neonatal neurons, adult CNS neurons cannot regenerate injured axons (Chen et al., 1995; Moore et al., 2009) possibly due to the inhibitory environment created by mature oligodendrocytes and astroglia (Yiu and He, 2006), which form a glial scar after myelin sheath degeneration in MS/EAE (Steinman et al., 2002; Frohman, 2003). Yet strategies targeting the astroglial inhibitory cues in EAE animal models resulted in only modest regeneration (Bartsch et al., 1995; Kim et al., 2003). However, embryonic neurons are found to readily grow past these inhibitory cues in CNS when transplanted, thus indicating a role for intrinsic developmentally regulated factors in inhibiting the axon growth and regeneration in adult CNS neurons (Lu et al., 2012). Thus, the hypothesis for this study was that the knock-out (KO) of intrinsic axon growth inhibitory factors in injured CNS neurons can promote axon regeneration thereby aiding in the restoration of visual function in MS and optic neuritis. cAMP (Cai et al., 2001), cAMP response element-binding protein (CREB; Gao et al., 2004), B cell lymphoma/leukemia (Bcl-2; Cho et al., 2005), anaphase promoting complex (APC) signaling pathways (Konishi et al., 2004), phosphatase and tensin homology (PTEN; Park et al., 2008), and zinc finger containing Krüppel-like transcription factors (KLFs; Moore et al., 2009) were identified among the most potent intracellular signaling molecules. Among these factors, KLF4 expression was found to be developmentally regulated and was demonstrated to possess a strong inhibitory effect on axonal growth and/or regeneration in injured and healthy adult CNS neurons (Moore et al., 2009). Conditional KO of the Klf4 gene in rat primary RGCs in vitro and in a rat ON crush model in vivo resulted in robust axonal regeneration and growth (Moore et al., 2009). For this reason, in the current study we decided to test whether targeted Klf4 gene deletion after the disease onset could alleviate optic neuritis in EAE-challenged mice.

\section{Materials and Methods}

\section{Animals}

Wild-type (WT) C57BL/6 mice were purchased from The Jackson Laboratory. Initial batch of Klf4 $4^{f / f t}$ mice were a kind gift from Jeffrey L. Goldberg, department of Ophthalmology, Byers Eye Institute at Stanford University, Stanford, CA. Heterozygous B6.129S6-Klf4tm1Khk/Mmmh mice were obtained from MMRRC-MO and were crossed with C57BL/6 to generate homozygous $K / f 4^{\text {fl/fl }}$ in C57BL/6 background. Age matched littermate controls were used for each experiment. Animals used were of either sex and number of eyes analyzed for each experiment were shown in Table 1. The protocol for the study was approved by the University Institutional Animal Care and Use Committee and all the procedures were conducted in accordance with the United States Public Health Service Policy on Humane Care and Use of Laboratory Animals. 
Table 1: Number of eyes analyzed for each experiment

Experiment Animal of eyes $(N)$

KIf4 expression analysis: Western blotting Mice 18

Cre-GFP immunofluorescence Mice 3

Electrophysiology (PERG) Mice 48

Electron microscopy axon counts $\quad$ Mice 9

RGC numbers immunofluorescence Mice 9

GAP43 Western $\quad$ Mice 18

\section{Plasmid constructs and recombinant AAV2 packaging}

SsAAV-CMV-Cre-ires-EGFP is a single stranded AAV plasmid in which the cDNAs of Cre recombinase and eGFP were cloned under cytomegalovirus (CMV) promoter. Presence of internal ribosomal entry site in between cre recombinase and reporter eGFP cDNAs allows, translation of separate Cre recombinase and EGFP proteins from single mRNA transcribed from CMV promotor. Expression of EGFP can be easily monitored with green fluorescence. ScAAV-CMV-mCherry was used as injection control.

Recombinant AAV2 particles carrying ssAAV-CMV-Creires-EGFP or a control scAAV-CMV-mCherry was produced by the plasmid cotransfection method (Hauswirth et al., 2000). Plasmids were amplified and purified using EndoFree plasmid mega kit (QIAGEN Inc.) and were packaged into AAV2 virions with triple tyrosine $(Y)$ to phenylalanine (F) mutations at positions 444, 500, and 730 (Y444F + Y500F + Y730F) in the VP3 capsid by transfection into human HEK 293 cells with standard procedures (Petrs-Silva et al., 2009, 2011). The crude iodixanol fractions were purified using the Pharmacia AKTA FPLC system (GE Healthcare Pharmacia), the virus was then eluted from the column with $215 \mathrm{~mm} \mathrm{NaCl}(\mathrm{pH} \mathrm{8.0)}$, and the recombinant AAV (rAAV) peak was collected. The rAAVcontaining fractions were then concentrated and bufferexchanged in Alcon balanced salt solution with $0.014 \%$ Tween 20 (Alcon Laboratories), with a Biomax 100-K concentrator (Millipore). Virus was then titered for DNase-resistant viral genomes by real-time $\mathrm{PCR}$ relative to a standard. Finally, the purity of the virus was validated by silver-stained SDS/PAGE, assayed for sterility and lack of endotoxin and then aliquoted and stored at $-80^{\circ} \mathrm{C}$ (Hauswirth et al., 2000).

\section{Induction of EAE and intravitreal injections}

Double floxed Klf4 adult mice and the littermates were sensitized for EAE by injecting $0.1 \mathrm{ml}$ of sonicated homologous spinal cord emulsion in complete Freunds adjuvant (CFA; Difco) subdermally into the nuchal area. Control littermates received subdermal inoculation with CFA. For intraocular injection of rAAV, mice were sedated by inhalation with 1.5-2\% isoflurane. A local anesthetic (proparacaine hydrochloride) was applied topically to the cornea and the pupils were dilated by using a drop of $1 \%$ tropicamide. A 32Gauge needle attached to a Hamilton syringe was inserted through the pars plana under the dissecting microscope. $K I f 4^{f I f I}$ mice sensitized for EAE received bilateral intravitreal injections of $1 \mu \mathrm{l}$ ssAAV-CMV-Cre-ires-EGFP $\left(4.95 \times 10^{12}\right.$ $\mathrm{vg} / \mathrm{ml})$. EAE-sensitized littermates received $1 \mu \mathrm{l}$ of scAAV-
CMV-mCherry $\left(9.41 \times 10^{11} \mathrm{vg} / \mathrm{ml}\right)$ as disease controls. CFA animals received $1 \mu \mathrm{l}$ of scAAV-CMV-mCherry $\left(9.41 \times 10^{11}\right.$ $\mathrm{vg} / \mathrm{ml}$ ) as injection controls and/or age matched unsensitized mice served as additional controls. For clarity, we now on use following terminology for describing these three groups as (1) EAE-KIf4 ${ }^{f l / f l}$-Cre-ttd, (2) EAE-vehicle (Veh)-ttd, and (3) control-Veh-ttd mice groups.

We have performed two separate sets of experiments as shown in experimental schematic diagram (Fig. 1). In the first set of experiments (Group I), EAE sensitization and intravitreal injections were performed simultaneously (Fig. 1A). Whereas, in the second set of experiments (Group II) mice were first sensitized for EAE and were followed up for a significant drop in PERG amplitudes compared with CFA controls and then the intravitreal injections were performed (Fig. 1B).

\section{Pattern electroretinography (PERG)}

Serial PERGs were obtained at various time points for all mice groups, control-Veh-ttd ( $n=16$ eyes), EAE-Vehttd ( $n=16$ eyes), and EAE-KIf $4^{f l / f l}$-Cre-ttd mice $(n=16$ eyes) as shown in schematic (Fig. 1). PERGs in the mouse was recorded as reported by Porciatti group (Nagaraju et al., 2007; Porciatti, 2007; Porciatti et al., 2007). Briefly, mice were weighed and anesthetized by intraperitoneal injection of ketamine/xylazine hydrochloride solution (ketamine $80 \mathrm{mg} / \mathrm{kg}$ body weight and xylazine $10 \mathrm{mg} / \mathrm{kg}$ body weight). Mice were gently restrained with the use of bite bar and a nose holder to allow unobstructed vision. Body temperature was maintained at $37^{\circ} \mathrm{C}$ using a feedback-controlled heating pad. The eyes of anesthetized mice were wide open and steady, with un-dilated pupils pointing laterally and upward. The ERG electrode (0.25$\mathrm{mm}$ diameter silver wire configured to a semicircular loop of $2-\mathrm{mm}$ radius) was placed on the corneal surface and it was positioned in such a way as to encircle the pupil without limiting the field of view. Reference and ground electrodes made of stainless-steel needles were inserted under the skin of the scalp and tail, respectively. A small drop of balanced saline was topically applied on the cornea to prevent drying during recording. A visual stimulus of contrast-reversing bars (field area, $50^{\circ} \times 58^{\circ}$; mean luminance, $50 \mathrm{~cd} / \mathrm{m}^{2}$; spatial frequency, $0.05 \mathrm{cyc} /{ }^{\circ}$; contrast, 100\%; temporal frequency, $1 \mathrm{~Hz}$ ) was aligned with the projection of the pupil at a distance of $20 \mathrm{~cm}$. Retinal signals were amplified by 10,000-fold and bandpass filtered by $1-30 \mathrm{~Hz}$. Three consecutive responses to each of the 600 contrast reversals were recorded and checked for their consistency by superimposition and then were averaged. Averaged PERG values were analyzed to evaluate the major positive and negative waves using commercially available software (Sigma Plot; Systat Software Inc.).

\section{AAV-mediated Cre recombinase, EGFP expression, and KIf4 KO and growth-associated protein 43 (GAP43) expression in mice RGCs}

Western blotting

Total protein fractions isolated from retina and ONs from the control mice and $K / f 4^{f l / f l}$ mice euthanized at one- 

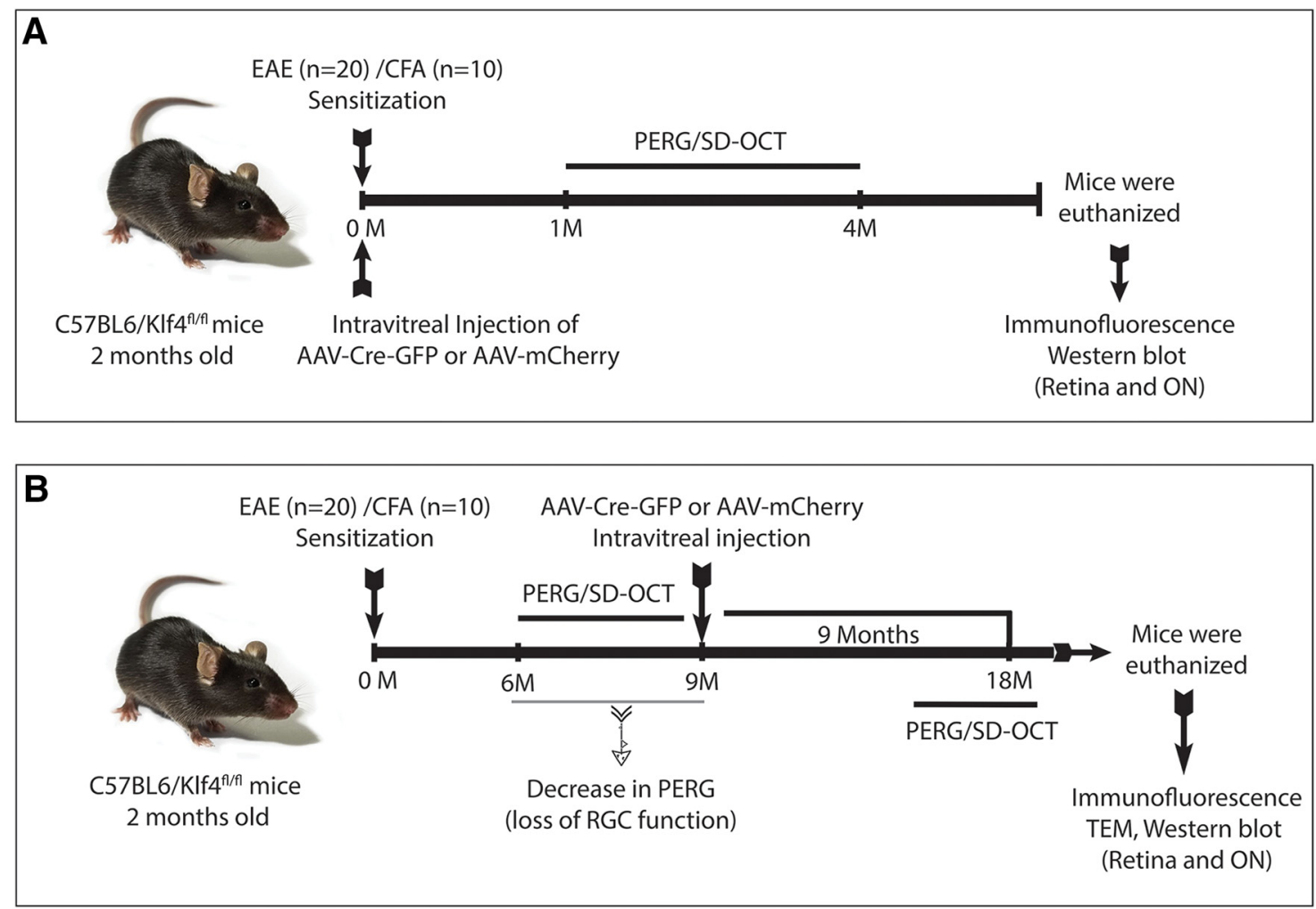

Figure 1. Schematic showing experimental design. A, Experimental design for simultaneous EAE sensitization and rescue injections (Group I). B, Experimental design for Group II mice experiments where rescue injections were performed after the significant decrease in PERGs. PERG, Pattern electroretinograms; SD-OCT, Spectral domain optical coherence tomography.

month postinjection (MPI) of ssAAV-CMV-Cre-ires-EGFP were used for KLF4 protein expression analysis $(n=6$ eyes/group). Retina and ON protein samples isolated from $9 \mathrm{MPI}$ to $18 \mathrm{MPS}$ of control-Veh-ttd mice $(n=6$ eyes), EAE-Veh-ttd ( $n=6$ eyes), and EAE-KIf4 $4^{f l / f l}$-cre-ttd ( $n=6$ eyes) mice were used for GAP43 expression analysis. Briefly, tissues were washed twice in ice cold PBS, resuspended in Pierce RIPA buffer (Thermo Scientific) containing Pierce protease inhibitor (Thermo Scientific), homogenized using hand held battery operated tissue homogenizer (VWR International LLC), quantified using BioRad Dc protein assay kit (Bio-Rad) and stored at $-20^{\circ} \mathrm{C}$ until use. Equal amounts of protein were loaded on the 4$12 \%$ NuPAGE Bis-Tris gels (Invitrogen) and were electrotransferred onto PVDF membranes. Membranes were blocked in TBST containing $5 \%$ non-fat dry milk and $0.5 \%$ Tween 20 for $1 \mathrm{~h}$ and incubated with respective primary antibodies that included rabbit polyclonal to GFP (Abcam catalog \#ab290, RRID:AB_303395), rabbit polyclonal to KLF4 (Abcam catalog \#ab72543, RRID:AB 1269261), rabbit polyclonal to GAP43 (Abcam catalog \#ab16053, RRID:AB_443303), and rabbit polyclonal to GAPDH (Cell Signaling Technology catalog \#2118, RRID: AB_561053). The membranes were washed three times with TBST buffer and incubated with the goat anti rabbit IgG conjugated with horseradish peroxidase (HRP) secondary antibody (Santa Cruz Biotechnology). Membranes were then washed in TBST buffer three times and immunodetected using the enhanced chemiluminescence
(ECL) system (GE Healthcare). Band intensities were quantitated by using ImageJ-NIH software.

\section{Immunofluorescence}

One month after intravitreal injection of ssAAV-CMVCre-ires-EGFP, KIf4 $4^{f l / f l}$ mice were euthanized and eyeballs and ONs were fixed in 4\% PFA for $1 \mathrm{~h}$ ( $n=3$ eyes/group). Retina and ONs were dissected out and retinal whole mounts and cryosections of retina and ONs were immuno-stained for rabbit polyclonal to GFP (Abcam catalog \#ab290, RRID:AB_303395) and rat monoclonal to Thy1 (Abcam catalog \#ab85352, RRID:AB_1861402) antibodies and were imaged on Zeiss LSM 700 confocal microscope (Zeiss LSM 700; Zeiss).

\section{Histology and ultrastructure}

Eighteen months after EAE sensitization and nine months post rAAV rescue injections, all the mice were overdosed with sodium pentobarbital. They were then perfused by cardiac puncture with PBS and then with fixative consisting of $4 \%$ paraformaldehyde in $0.1 \mathrm{M}$ PBS buffer $(\mathrm{pH} 7.4)$.

\section{RGC counts-immunofluorescence}

The eyeballs and ONs were dissected out and fixed in $4 \%$ paraformaldehyde in PBS for $1 \mathrm{~h}$ and then $0.4 \%$ paraformaldehyde overnight ( $n=3$ eyes/group). Cornea and lens were removed, and the retina was dissected from the eyecup. Four radial cuts were made to flatten the retina. 
After three washes in PBS, the retinal tissues were permeabilized with $0.5 \%$ Triton X-100 (Dow Chemical Corporation) in PBS for $1 \mathrm{~h}$, then blocked with $10 \%$ goat serum containing $0.5 \%$ Triton $\mathrm{X}-100$ for $1 \mathrm{~h}$. The flat-mounted retinas were rinsed in PBS and incubated with a rabbit monoclonal anti-Tuj1 (1:200; Covance catalog \#MRB-435P-100, RRID:AB_663339) antibody overnight at $4^{\circ} \mathrm{C}$. Flat mounted retinas were washed with PBS three times (5 min each) and incubated in 1:500 dilution of goat anti-rabbit Cy3 (Tuj1) or goat anti-rabbit Cy2 antibodies (Jackson ImmunoResearch), along with 4",6-diamidino-2-phenylindole $(2 \mu \mathrm{g} / \mathrm{ml}$; Santa Cruz Biotechnology Inc.), at $4^{\circ} \mathrm{C}$ overnight. The working concentrations of primary and secondary antibodies were prepared in $10 \%$ goat serum in PBS $(\mathrm{pH}$ 7.4) containing $0.2 \%$ Triton $\mathrm{X}-100$. The retinas were washed three times (5 min each time) in PBS and then transferred to glass slides with the RGC layer facing up. Retinal tissues were observed under a confocal microscope (Zeiss LSM 700; Zeiss). Images were obtained from all four quadrants of the retina and the number of Tuj1-positive cells were counted and mean \pm SE number of cells per $\mathrm{mm}^{2}$ were evaluated and plotted as box and whisker plots.

\section{Ultrastructural analysis}

The eyes with attached ONs ( $n=3$ eyes/group) were dissected out and further processed by immersion fixation in $2.5 \%$ glutaraldehyde, postfixed in $1 \%$ osmium tetroxide, $0.1 \mathrm{M}$ sodium cacodylate-HCl buffer $(\mathrm{pH} 7.4), 7 \%$ sucrose (cold), and then dehydrated through an ethanol series to propylene oxide, infiltrated, and embedded in epoxy resin that was polymerized at $60^{\circ} \mathrm{C}$ overnight. Semi-thin sections $(0.5 \mu \mathrm{m})$ of the $\mathrm{ONs}$ were obtained and stained with toluidine blue for light microscopic examination. Ultrathin sections ( $90 \mathrm{~nm}$ ) were also obtained from all the mice and were placed on nickel grids and imaged on JEOL JEM-1400 transmission electron microscope, operating at $80 \mathrm{kV}$. Forty images from each $\mathrm{ON}$ were imaged randomly covering the entire $\mathrm{ON}$ region by an individual masked for the treatment groups. Axon counts, axon diameters, myelin thickness and mitochondrial number and diameters were analyzed using ImageJ-NIH software.

\section{Statistical analyses}

Statistical analyses were performed using GraphPad Prism 6 software. All datasets were analyzed using the KS normality test for normality. One-way ANOVA followed by Tukey's multiple comparison tests with multiplicity adjusted $p$ values were used to compare when more than two groups were present. Two-way ANOVA followed by Tukey's multiple comparison tests were used to compare the groups when time point is another variable. For axon distribution, myelin thickness and mitochondrial size analyses, we performed two-way ANOVA followed by $t$ test, and statistical significance was determined using the Holm-Sidak method, with $\alpha=5 \%$. Computations assume that all rows are samples from populations with the same scatter (SD). All comparison tests were two-tailed; $p<0.05$ was considered statistically significant. Values were expressed as mean $\pm \mathrm{SE}$.

\section{Results}

\section{SsAAV-CMV-Cre-ires-EGFP efficiently transduces RGCs and KO the KLF4 expression}

Immunofluorescence analysis was performed on ON longitudinal sections and retinae obtained one-month postintravitreal injection of ssAAV2-CMV-Cre-ires-EGFP (Fig. $2 A$ ) in $K / f 4^{f l / f l}$ mice. Longitudinal sections of ON show DAPI-labeled resident cell nuclei (Fig. 2B) and abundant expression of GFP in RGC axonal bundles (Fig. 2C). Retinal whole mounts of the Cre-GFP-injected mice showed the DAPI-labeled cell nuclei (Fig. 2D) expressing GFP (Fig. 2E) in Thy1.2-positive RGCs (Fig. 2F) and merged image (Fig. 2G). Longitudinal sections of the retina show DAPI-positive nuclei in all three retinal layers (Fig. 2H). However, GFP expression was limited to the cells in the RGC layer (Fig. 2l) that were positive for the Thy 1.2 RGC marker (Fig. 2J) and merged image (Fig. 2K). Immunoblotting of retina samples showed expression of GFP in the mice injected with ssAAV2-CMV-Cre-iresEGFP and was absent in un-injected control mice (Fig. $2 L)$. Reduced expression of KLF4 was evident in $K I f 4^{f l / f l}$ mice injected with ssAAV2-CMV-Cre-ires-EGFP compared with un-injected control mice while the GAPDH levels remained similar in both the groups (Fig. 2L). ImageJ analysis showed a $70 \%$ reduction in the KLF4 band intensity in SSAAV-CMV-Cre-ires-EGFP-injected mice compared with uninjected controls ( $p<0.001$; Fig. $2 M)$, indicating cre recombinase mediated $\mathrm{KO}$ of KLF4 in RGCs and ONs of ssAAV-CMV-Cre-ires-EGFP-injected mice.

\section{KIf4 KO in RGCs rescues RGC and on function in EAE mice: PERG}

PERG, a sensitive measure of RGC function, was used to evaluate the visual function and progression of optic neuritis in mice. PERGs were recorded for all three groups of mice, i.e., EAE-KIf4 $4^{f l f l}$-Cre-ttd mice, EAE-Veh-ttd mice and control-Veh-ttd mice at $1 \mathrm{MPI}$ and $4 \mathrm{MPI}$ (Group I; Fig. 3A). Two-way ANOVA followed by Tukey's multiple comparison test with $p$ values adjusted for multiple groups of animals over time showed highly significant difference among the control-Veh-ttd, EAE-Veh-ttd, and EAE-KIf $4^{f l / f l}$-Cre-ttd mice at one and four months postsensitization (MPS; Table 2). Compared with control-Veh-ttd mice, PERG amplitudes of EAE-Veh-ttd mice decreased progressively from $28 \%$, at one month $(p=0.011)$ to $56 \%$ at four months $(p<0.0001)$. On the other hand, Cre recombinase-mediated $\mathrm{KO}$ of Klf4 gene in RGCs of EAE$K I f 4^{f l / f l}$-Cre-ttd mice rescued PERG amplitudes significantly compared with EAE-Veh-ttd mice at both the time points tested $p=0.038$ at one month and $p=0.0001$ at four months). On the other hand, PERG amplitudes of EAE-KIf ${ }^{f l / f l}$-Cre-ttd mice at one month were comparable to control-Veh-ttd mice but decreased significantly at four months ( $p=0.04$; Fig. $3 A$; Table 2). 
A

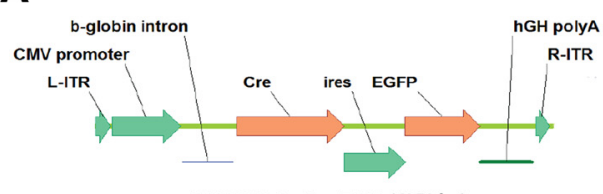

PAAV-CMV-Cre-ires-EGFP (4353 bp)
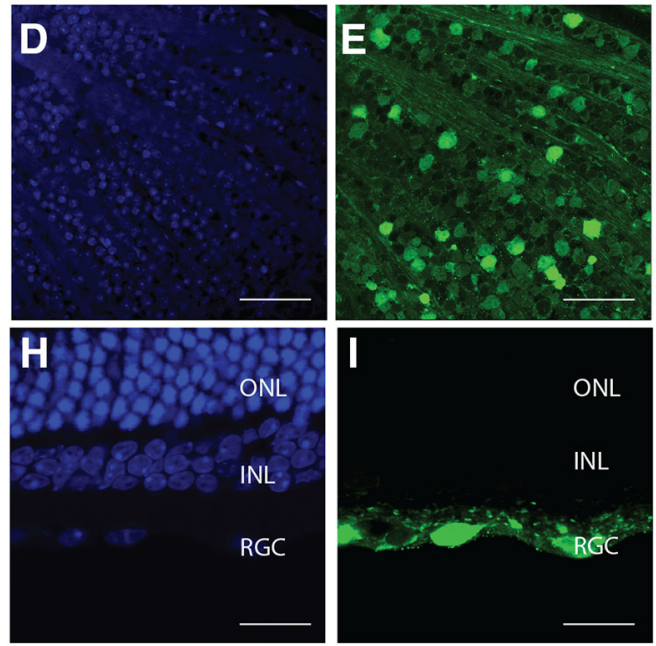

$\mathbf{L}$

Control AAV2-Cre-EGFP

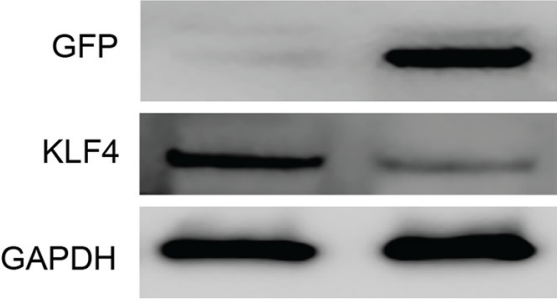

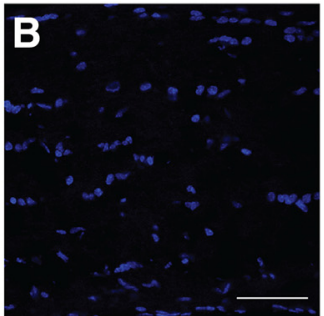
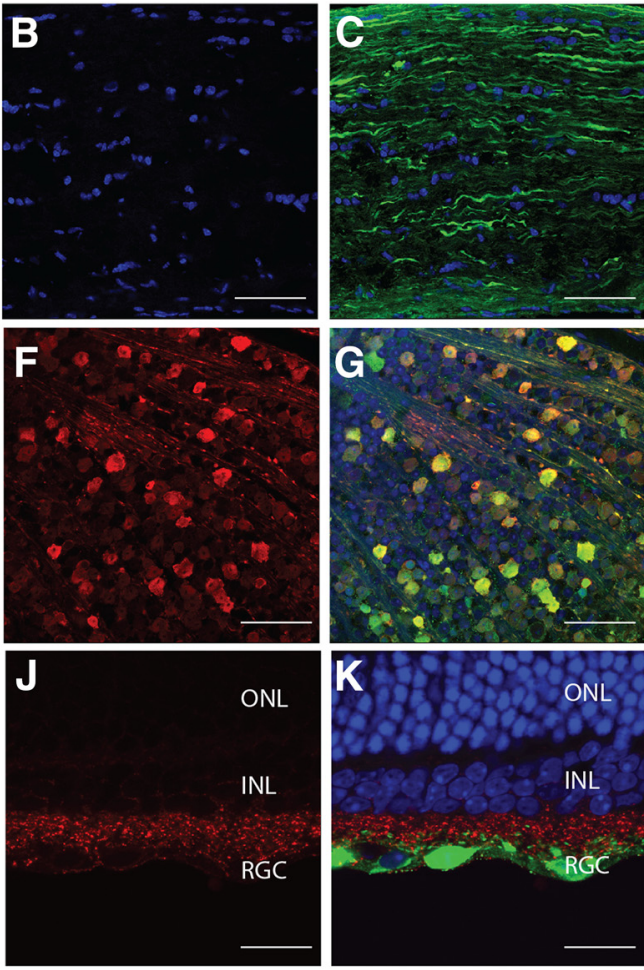

M

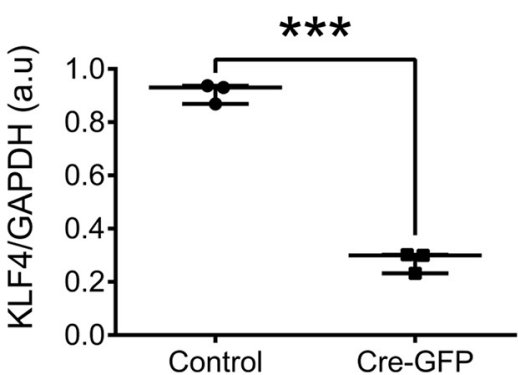

Figure 2. Conditional KO of KIf4 gene in the retina using rAAV2-Cre-GFP. A, Schematic of the AAV2-Cre-EGFP vector. L-ITR: Left inverted terminal repeat; R-ITR: right inverted terminal repeat; Cre: Cre recombinase; ires: internal ribosome entry site; EGFP: enhanced green fluorescent protein; hGH poly A: bGH Poly adenylation signal. $\boldsymbol{B}, \boldsymbol{C}$, Immunostaining of ON longitudinal sections of one month after AAV-Cre-ires-EGFP injection mice showed DAPI-labeled ON resident cells (B) and GFP-labeled axon bundles (C). $\boldsymbol{D}-\mathbf{G}$, Immunostaining of retinal whole mounts at one month after AAV-Cre-ires-EGFP injection showed DAPI-labeled cell nuclei (D), GFP-positive cells $(\boldsymbol{E})$, Thy1.2-positive RGCs $(\boldsymbol{F})$, and co-localization of GFP in RGCs shown in merged image (G). $\boldsymbol{H}-\boldsymbol{K}$, Corresponding longitudinal sections showing DAPI-positive nuclei in all three retinal layers $(\boldsymbol{H})$, GFP-expressing cells in RGC layers $(\boldsymbol{I})$, stained positive for Thy1.2 RGC marker $(\boldsymbol{J})$, and all three channels merged $(\boldsymbol{K}) ; n=3$ eyes. $\boldsymbol{L}$, Immunoblotting of retina samples obtained one month after intravitreal injection of ScAAV-CMV-Cre-ires-EGFP into KIf4 ${ }^{f l / f l}$ mice shows selective expression of GFP and decreased expression of KLF4 compared with control retina. The housekeeping GAPDH expression is shown in injected versus control retina. $\boldsymbol{M}$, Box-whisker plot shows ImageJ quantitation of KLF4 knock-down in AAV-cre-GFP versus control. Box-plot elements include, center line, median; box limits, upper 75th and lower 25th percentile of the data; whiskers, lowest and highest data points. Samples derived from the same experiment and that gels/blots were processed in parallel for quantitative analysis. ONL, outer nuclear layer; INL, inner nuclear layer; RGC, RGC layer (*** $p=0.0001-0.0009$; unpaired Student's $t$ test; $n=6$ eyes/group). Figure Contributions: Venu Talla acquired the data and generated the figure.

We next looked at the PERG amplitudes of the EAEsensitized KIf4 ${ }^{f l f l}$ mice that received SSAAV-CMV-Creires-EGFP intravitreal injections following a significant drop in PERG amplitudes (9MPS) and compared with the control and EAE-sensitized littermates mock treated with AAV2 mCherry (Group II mice). At baseline (i.e., before sensitization) the mean PERG amplitudes were indistinguishable among all three groups (i.e., control, EAE, and EAE-KIff ${ }^{f l / f l}$ mice; Table 3). However, at 9 MPS, two-way
ANOVA indicated significant differences in mean PERG amplitudes among control, EAE littermates and EAE-sensitized KIf4 ${ }^{f l / f l}$ mice (Table 3). While the drop in PERG amplitudes among EAE littermates and EAE KIf4 ${ }^{f / / f l}$ mice were comparable $(p=0.99)$, these two groups showed significantly decreased PERG amplitudes compared with controls at 9MPS ( $p \leq 0.001$; Fig. 3B,C; Table 3$)$. At this time, EAE-sensitized $K I f 4^{f l / f l}$ mice received intravitreal injection of SSAAV-CMV-Cre-ires-EGFP into both eyes 

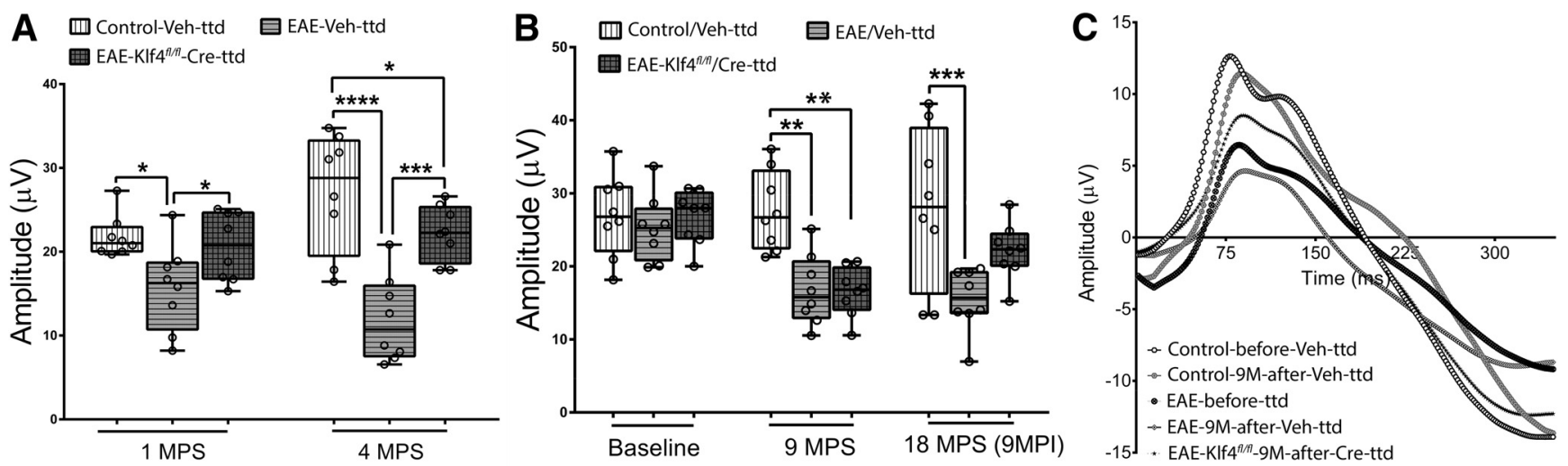

Figure 3. PERG analysis, rescue of visual function. $\boldsymbol{A}$, Box and whisker plot showing PERG amplitudes of control-Veh-ttd, EAE-Veh$\mathrm{ttd}$, and EAE-KIf4 ${ }^{f / f l}$-Cre-ttd mice at 1 and 4 MPS where EAE sensitization and intravitreal injections were done simultaneously $(n=8$ eyes/group). B, Box and whisker plot showing PERG amplitudes of Control, EAE and EAE-KIf4 ${ }^{\text {fl/fl }}$ mice at 9 MPS versus 18 MPS + 9 $\mathrm{MPI}$ of Veh-ttd or Cre-ttd mice. Box-plot elements include, center line, median; box limits, upper 75th and lower 25th percentile of the data; whiskers, lowest and highest data points. $\boldsymbol{C}$, Representative PERG wave forms of CFA, EAE and EAE KIf4 ${ }^{f l / f l}$ mice at 9 MPS versus $18 \mathrm{MPS}+9 \mathrm{MPI}$ of scAAV-CMV-mCherry or sSAAV-CMV-Cre-ires-GFP. PERGs were recorded three times for each mice/time point and mean PERGs with subtracted background was used for final analysis. Statistical analysis was performed by two-way ANOVA followed by Tukey's multiple comparison test and $p$ values were adjusted for multiple sample comparisons, $p<0.05$ was considered to be statistically significant; $* p=0.01-0.05 ; * * p=0.001-0.009 ; * * * p=0.0001-0.0009$, $* * * * p<0.0001 ;(n=8$ eyes for each group). Figure Contributions: Venu Talla acquired the data, analyzed, and generated the figure.

whereas, the EAE littermates and controls received scAAV2-CMV-mCherry injections. Nine months after AAV injection (9 or 18 MPS) PERGs were recorded again for all the groups and amplitudes were compared. At $9 \mathrm{MPI}$, the EAE-Veh-ttd mice continued to show a significant drop in PERG amplitudes compared with control-Veh-ttd mice $(p=0.0002)$ whereas, the PERG amplitudes were improved in EAE-KIf4 ${ }^{\text {fl/fl}}$-Cre-ttd mice and were comparable to control-Veh-ttd group ( $p=0.092$; Table 3). These PERG results from Group I and Group II mice indicated that CreGFP-mediated KO of KIf4 $4^{f l / f l}$ gene in EAE/optic neuritis mice not only prevents RGC loss, but also restored the function of remaining, albeit injured RGCs.

\section{KIf4 KO in RGCs prevents EAE-mediated RGC loss}

The number of RGCs in retinal whole mounts were quantified by immunostaining with Tuj1 antibody. Representative confocal images of retinal whole mounts and corresponding longitudinal sections shows Tuj1-stained RGCs in control-Veh-ttd mice (Fig. 4A-D), EAE-Veh-ttd mice (Fig. 4E-H) and EAE-KIf4 $4^{f l / f I}$-Cre-ttd mice (Fig. 4I-L), at 18 MPS. Quantitative analysis revealed $82 \%$ loss of Tuj1-positive RGCs in EAE-Veh-ttd $\left(602 \pm 271\right.$ per $\mathrm{mm}^{2}$, average \pm SE, $p=0.0002$ ) and $52 \%$ loss in EAE-KIff $\left.\right|^{f / / f_{-}^{\prime}}$ Cre-ttd mice (1657 \pm 74 per $\left.\mathrm{mm}^{2} ; p=0.002\right)$ compared with control-Veh-ttd mice (3482 \pm 222 per $\mathrm{mm}^{2}$; Fig. 4M). This correspond to a $37 \%$ rescue in RGC numbers in EAE$K I f 4^{f l / f l}$-Cre-ttd mice when compared with EAE-Veh-ttd mice $(p=0.02$; Fig. $4 M)$. However, in the case of the first group of experiments where rescue and sensitization were done simultaneously, $48 \%(p=0.001)$ of RGCs were lost in EAE-Veh-ttd and $23 \%(p<0.05)$ loss in EAE-KIf4 $4^{f / f l}$-Crettd mice when compared with control-Veh-ttd mice (Fig. $4 N$ ). This corresponds to a $52 \%$ rescue in RGCs of EAEKIf4 ${ }^{\text {fl/fl}}$-Cre-ttd mice compared with EAE-Veh-ttd mice $(p<0.05)$. In summary, RGC loss was considerably lower in EAE-KIf4 ${ }^{\text {fl/fI}}$-Cre-ttd mice compared with EAE littermates regardless of time at which rescue injection was performed (simultaneously with EAE sensitization vs after PERG

Table 2: PERG amplitudes-Group I

Tukey's multiple comparison test $p$ value and $95 \%$ confidence interval $(\mathrm{Cl})$

\begin{tabular}{|c|c|c|c|c|c|c|c|}
\hline $\begin{array}{c}\text { Group I } \\
\text { (mice groups) }\end{array}$ & $\begin{array}{l}\text { Time points } \\
\text { (MPI) }\end{array}$ & $\begin{array}{r}\text { Amplitude }(\mu \mathrm{V} ; \\
\text { mean } \pm \mathrm{SEM})\end{array}$ & $\begin{array}{l}\text { KS normality } \\
\text { test ( } p \text { value) }\end{array}$ & $\begin{array}{l}\text { Two-way ANOVA } \\
\text { ( } p \text { value) }\end{array}$ & $\begin{array}{l}\text { Control-Veh-ttd (vs) } \\
\text { EAE-Veh-ttd }\end{array}$ & $\begin{array}{l}\text { Control-Veh-ttd (vs) } \\
\text { EAE-KIf4 }{ }^{f l / f I} \text {-Cre-ttd }\end{array}$ & $\begin{array}{l}\text { EAE-Veh-ttd (vs) } \\
\text { EAEKIf4 }{ }^{f l f f l} \text {-Cre-ttd }\end{array}$ \\
\hline Control-Veh-ttd & 1 & $21.78 \pm 0.89$ & $>0.1$ & Row factor: & $p=0.0110$ & $p=0.796$ & $p=0.038$ \\
\hline EAE-Veh-ttd & 1 & $15.69 \pm 1.83$ & $>0.1$ & $p=0.53$ & Cl: & $\mathrm{Cl}:$ & Cl: \\
\hline EAE KIf4 ${ }^{f / / f l}-$ Cre-ttd & 1 & $20.62 \pm 1.48$ & $>0.1$ & column factor: & 1.416 to 10.75 & -3.513 to 5.823 & -9.597 to -0.2614 \\
\hline Control-Veh-ttd & 4 & $27.1 \pm 2.49$ & $>0.1$ & $p<0.0003$ & $p<0.0001$ & $p=0.040$ & $p=0.0001$ \\
\hline EAE-Veh-ttd & 4 & $11.93 \pm 1.80$ & $>0.1$ & interaction: row & $\mathrm{Cl}:$ & $\mathrm{Cl}:$ & Cl: \\
\hline EAE-KIf $4^{f l \mid f l}-$ Cre-ttd & 4 & $22.2 \pm 1.16$ & $>0.1$ & $\begin{array}{l}\text { factor } \times \text { column factor: } \\
\boldsymbol{p}<\mathbf{0 . 0 0 9 8}\end{array}$ & 10.51 to 19.84 & 0.2089 to 9.545 & -14.96 to -5.628 \\
\hline
\end{tabular}

Bold indicates statistically significant difference of $p$ values. 
Table 3: PERG amplitudes-Group II

Tukey's multiple comparison test $p$ value and $95 \%$ confidence interval $(\mathrm{Cl})$

\begin{tabular}{|c|c|c|c|c|c|c|c|}
\hline $\begin{array}{l}\text { Group II } \\
\text { (mice groups) }\end{array}$ & $\begin{array}{l}\text { Time } \\
\text { points }\end{array}$ & $\begin{array}{l}\text { Amplitude } \\
(\mu \mathrm{V} ; \text { mean } \pm \mathrm{SEM})\end{array}$ & $\begin{array}{l}\text { KS normality } \\
\text { test } \\
\text { ( } p \text { value) }\end{array}$ & $\begin{array}{l}\text { Two-way ANOVA } \\
\text { ( } p \text { value) }\end{array}$ & $\begin{array}{l}\text { Control/Veh-ttd (vs) } \\
\text { EAE/Veh-ttd }\end{array}$ & $\begin{array}{l}\text { Control/Veh-ttd (vs) } \\
\text { EAE-KIf4 } 4^{f l f l} / \text { Cre-ttd }\end{array}$ & $\begin{array}{l}\text { EAE/Neh-ttd (vs) } \\
\text { EAE } K l f 4^{f l f l} / \text { Cre-ttd }\end{array}$ \\
\hline Control & Baseline & $26.93 \pm 1.99$ & $>0.1$ & Row factor: & $p=0.808$ & $p=0.99$ & $p=0.846$ \\
\hline EAE & Baseline & $25.21 \pm 1.60$ & $>0.1$ & $p=0.0100$ & Cl: & Cl: & Cl: \\
\hline $\mathrm{EAE}-K I f 4^{f l / f l}$ & Baseline & $26.74 \pm 1.31$ & $>0.1$ & column factor: & -5.102 to 8.54 & -6.624 to 7.022 & -8.344 to 5.301 \\
\hline Control & 9 MPS & $27.60 \pm 1.92$ & $>0.1$ & $p=0.0003$ & $p=0.001$ & $p=0.001$ & $p=0.99$ \\
\hline EAE & 9 MPS & $16.74 \pm 1.70$ & $>0.1$ & interaction: row factor $\mathrm{x}$ column & Cl: & Cl: & Cl: \\
\hline $\mathrm{EAE}-K I f 4^{\text {fl/fl}}$ & 9 MPS & $16.52 \pm 1.19$ & $>0.1$ & factor: $p=0.028$ & 4.037 to 17.68 & 4.264 to 17.91 & -6.596 to 7.049 \\
\hline Control-Veh-ttd & $\begin{array}{l}18 \mathrm{MPS} \\
(9 \mathrm{MPI})\end{array}$ & $28.11 \pm 3.87$ & $>0.1$ & & $\begin{array}{l}p=0.0002 \\
\mathrm{Cl}:\end{array}$ & $\begin{array}{l}p=0.092 \\
\mathrm{Cl}:\end{array}$ & $\begin{array}{l}p=0.057 \\
\mathrm{Cl}:\end{array}$ \\
\hline EAE-Veh-ttd & $\begin{array}{l}18 \mathrm{MPS} \\
(9 \mathrm{MPI})\end{array}$ & $15.46 \pm 1.52$ & $>0.1$ & & 5.819 to 19.46 & -0.8202 to 12.82 & -13.46 to 0.1831 \\
\hline EAE-KIf $4^{f l / f l}-$ Cre-ttd & $\begin{array}{l}18 \mathrm{MPS} \\
(9 \mathrm{MPI})\end{array}$ & $22.10 \pm 1.36$ & $>0.1$ & & & & \\
\hline
\end{tabular}

Bold indicates statistically significant difference of $p$ values.

amplitude dropped). Higher RGC survival in Group I mice or rescue before injury is as expected. In addition, increased RGC preservation in Cre-GFP injected EAE mice retina corroborates with improved RGC function as observed in our PERG experiments. Next, we checked whether KIf4 KO in EAE mice RGCs induce axonal regeneration that contributes to the visual function improvement in EAE mice.

\section{KIf4 KO in RGCs induces axonal regeneration in EAE mice ONs}

To gauge RGC axon regeneration and axon numbers, we used immunoblotting of GAP43 as a common surrogate marker for axonal regeneration, as well as transmission electron microscopic (TEM) analysis of ON samples obtained from the control-Veh-ttd, EAE-Veh-ttd, and EAE-KIf4 ${ }^{f l / f l}$-Cre-ttd mice euthanized after $18 \mathrm{MPS} / 9 \mathrm{MPI}$. Immunoblotting detected GAP43 expression in both ON (Fig. 5A) and retina (Fig. 5B) samples of all three groups tested (Fig. 5). However, ImageJ-based quantitative analysis of the GAP43 band intensities relative to GAPDH showed a significantly higher GAP43 ratio in EAE-KIf4 ${ }^{f l / f l}$ Cre-ttd mice compared with control and EAE littermates, indicative of active axonal regeneration in KIf4KO RGCs $(p<0.0001$; Fig. 5).

The ONs obtained from control-Veh-ttd, EAE-Veh-ttd, and EAE-KIf4 ${ }^{f l f I}$-Cre-ttd mice after 18 MPS were further used for histologic and TEM analysis. Light microscopic analysis of toluidine blue stained ON sections showed normal appearing axons and myelin in control-Veh-ttd mice (Fig. 6A) whereas, inflammatory cell infiltration and tissue fibrosis were evident in EAE-Veh-ttd (Fig. 6B) and EAE-KIf4 ${ }^{f l f l}$-Cre-ttd mice ONs (Fig. 6C). Further, transmission electron micrographs showed very minimal cellular infiltration in control-Veh-ttd ONs (Fig. 6D). In contrast, EAE characteristic astroglial cell infiltration and fibrosis were robust in EAE-Veh-ttd (Fig. 6E) and EAE-KIf4 ${ }^{\text {fl/fl}}$-Crettd mice ONs (Fig. 6F).
TEM images revealed normal myelinated axons in ONs of control-Veh-ttd mice (Fig. 7A-D), whereas all the hallmark features of MS, including the axonal loss, Wallerianlike axonal degeneration, demyelination, myelin degradation, axons with multiple degenerating mitochondria or lysosomes, small and/or swollen mitochondria with disoriented cristae, were evident in ONs of EAE-Veh-ttd mice (Fig. 7E-H). Nevertheless, unmyelinated axons and axons with thinner myelin were observed in higher percentages in EAE-KIf4 ${ }^{f l / f l}$-Cre-ttd mice (Fig. $7 /-L$ ). Quantitative analysis showed a $68.6 \%$ loss of axons in ONs of EAE-Veh-ttd $\left(7.29 \pm 0.27 / 100 \mu \mathrm{m}^{2}\right.$; average $\left.\pm \mathrm{SE} ; p=0.01 ; n=3\right)$ and $33.6 \%$ loss in EAE-KIf4 ${ }^{f l / f l}$-Cre-ttd mice $(15.4 \pm 2.45 / 100$ $\left.\mu \mathrm{m}^{2} ; p=0.16 ; n=3\right)$ compared with control-Veh-ttd control mice $\left(23.2 \pm 6.6 / 100 \mu \mathrm{m}^{2}\right.$; average $\pm \mathrm{SE} ; n=3$; Fig. $7 M)$. The axonal numbers in EAE-KIff ${ }^{f l f l}$-Cre-ttd ONs were significantly higher than EAE-Veh-ttd mice, indicating possible axonal rescue or regeneration on targeted KIf4 KO in RGCs of EAE-KIf4 $4^{f l / f l}$-Cre-ttd mice $(n=3$; $p<0.03$; Fig. 7M). When axon diameters were characterized, axons with $0.8-2.0 \mu \mathrm{m}$ in diameter (smaller diameter axons) were significantly lost in EAE-Veh-ttd and EAE$K I f 4^{f l / f l}$-Cre-ttd mice compared with control-Veh-ttd $(p<0.0001)$. However, we noted a significantly higher number of small caliber axons (range of $0.8-2.0 \mu \mathrm{m}$ ) in EAE-KIf $4^{f l / f l}$-Cre-ttd mice ONs $(p<0.05)$ compared with EAE-Veh-ttd, indicating possible axonal regeneration or rescue of these axons on KLF4-KO (Fig. 7N). Presence of unmyelinated axons and axons with thin myelin in the range of $0.06-0.12 \mu \mathrm{m}$ were significantly higher in EAE$K I f 4^{f l / f l}$-Cre-ttd mice compared with EAE-Veh-ttd mice $(p<0.05)$, further suggesting active axonal regeneration and remyelination in EAE-KIf4 ${ }^{\text {fl/fl}}$-Cre-ttd mice (Fig. 7O).

Mitochondria numbers per $100-\mu \mathrm{m}^{2}$ area of the $\mathrm{ON}$ showed no significant changes among the groups (Fig. 7P). However, small sized mitochondria (diameters $<0.4 \mu \mathrm{m}$ ) were found significantly higher in EAE-Veh-ttd mice compared with EAE-KIf ${ }^{f l / f l}$-Cre-ttd mice, $p=0.03$, pointing toward a pathologic mitochondrial fission and 

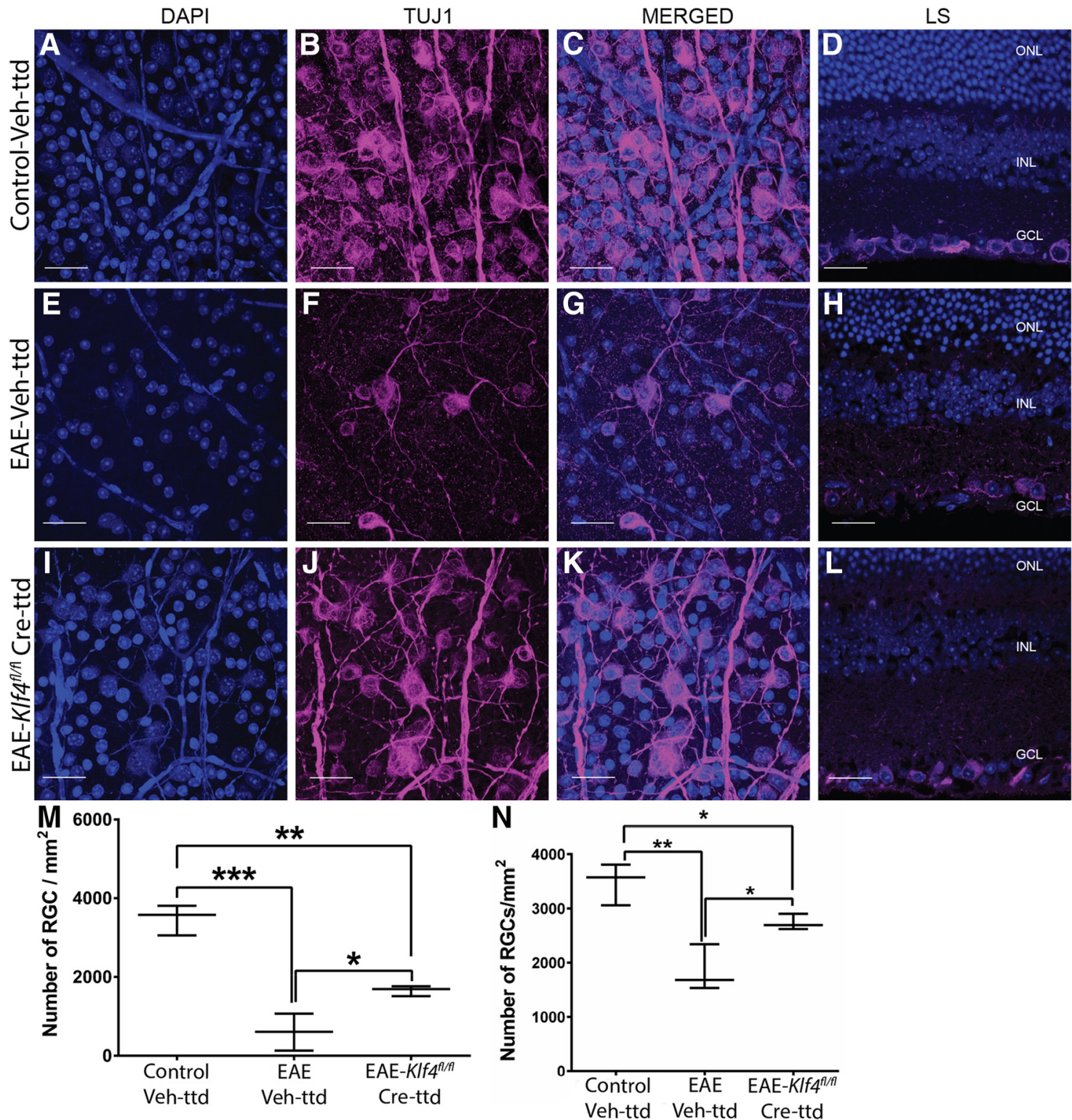

Figure 4. Retinal whole mounts and longitudinal sections: confocal microscopy of retinal whole mounts and corresponding longitudinal sections of $(\boldsymbol{A}-\boldsymbol{D})$ control-Veh-ttd, $(\boldsymbol{E}-\boldsymbol{H})$ EAE-Veh-ttd, and $(\boldsymbol{I}-\boldsymbol{L})$ EAE-KIf4 ${ }^{f / f t}$-Cre-ttd mice showing. (A, $\left.\boldsymbol{E}, \boldsymbol{I}\right)$ DAPI-positive cell nuclei, with $(\boldsymbol{B}, \boldsymbol{F}, \boldsymbol{J})$ Tuj1-positive RGCs, along with $(\boldsymbol{C}, \boldsymbol{G}, \boldsymbol{K})$ DAPI and Tuj1 merged images and $(\boldsymbol{D}, \boldsymbol{H}, \boldsymbol{L})$ representative retinal longitudinal sections with DAPI- and Tuj1-positive RGCs. Box and whisker plot $(\boldsymbol{M})$ compare the RGC counts in control-Veh-ttd, EAE-Veh-ttd, and EAE-KIf4 $4^{f l f l}$-Cre-ttd mice groups, in which ntravitreal injections were done after the PERGs were significantly decreased due to EAE. $\boldsymbol{N}$, Compares the RGC counts in control-Veh-ttd, EAE-Veh-ttd, and EAE-KIf4 $4^{f l f l}$-Cre-ttd mice groups, in which intravitreal injections and EAE sensitizations were done simultaneously. Box-plot elements include, center line, median; box limits, upper 75th and lower 25th percentile of the data; whiskers, lowest and highest data points. ONL, outer nuclear layer; INL, inner nuclear layer; RGC, RGC layer. Statistical analysis was performed by one-way ANOVA followed by Tukey's multiple comparison test, $p<0.05$ is considered to be statistically significant; $* p=0.01-0.05 ; * * p=0.001-0.009$, $* * * p=0.0001-0.0009 ; n=3$ eyes/group. Scale bars: $100 \mu \mathrm{m}$.

Figure Contributions: Venu Talla acquired the images. Rajeshwari Koilkonda did the RGC counting. Venu Talla generated the figure.

degradation process in EAE mice ONs (Fig. 7Q). Normal sized mitochondria $(0.5-1 \mu \mathrm{m}$ in diameter) were relatively higher in EAE-KIf4 $4^{f l / f l}$-Cre-ttd mice compared with EAEVeh-ttd mice indicating possible role for KLF4 in mitochondrial homeostasis.

\section{Discussion}

The axonal and neuronal degenerations responsible for progression of the disease begins early in optic neuritis/MS patients (Kuhlmann et al., 2002; Bjartmar et al., 2003). Despite anti-inflammatory therapies these patients 

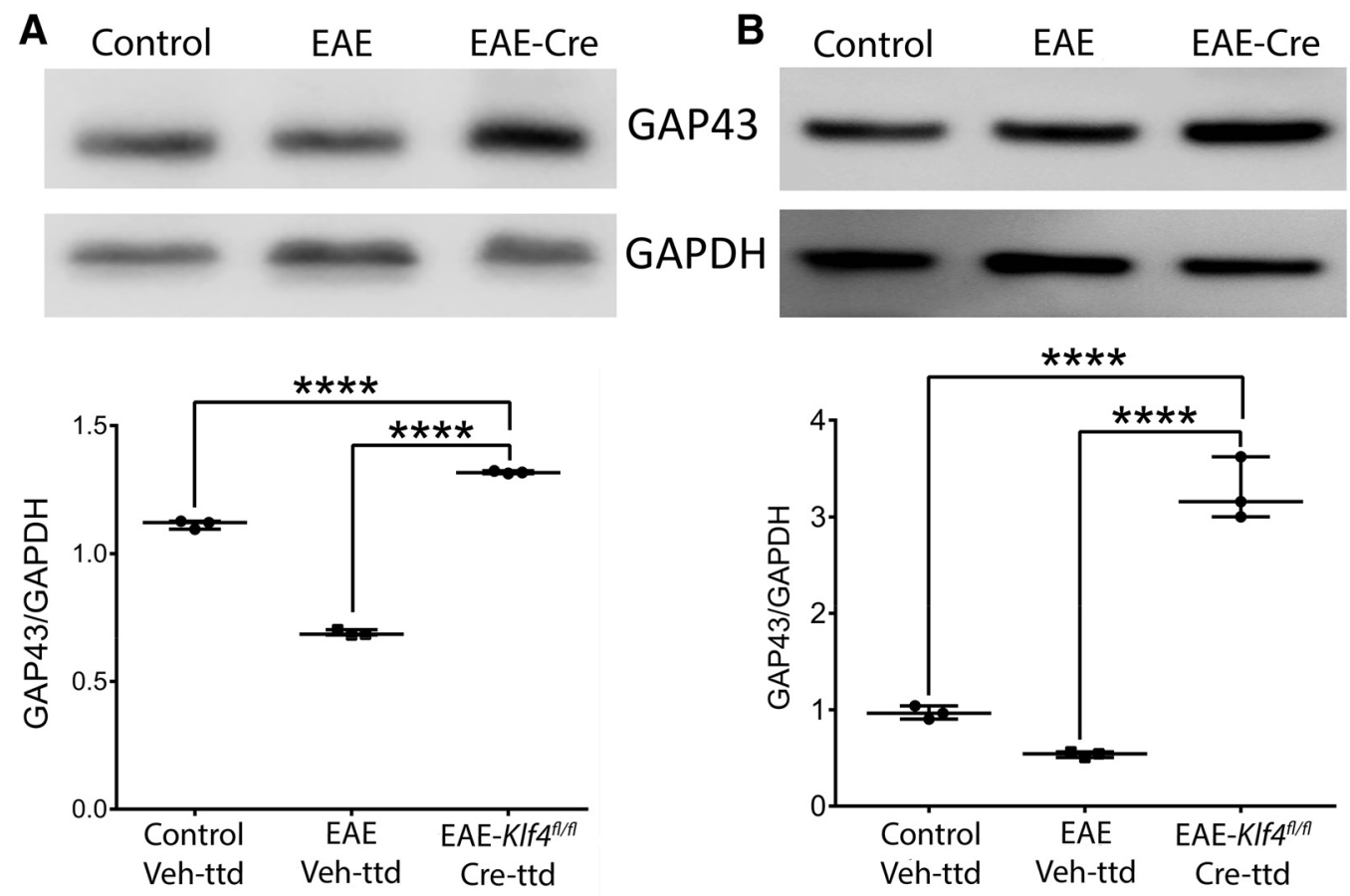

Figure 5. Axonal regeneration: immunoblotting of $(\boldsymbol{A}) \mathrm{ON}$ and $(\boldsymbol{B})$ retina samples obtained from $18 \mathrm{MPS} / 9 \mathrm{MPI}$ of control-Veh$\mathrm{ttd}$, EAE-Veh-ttd, and EAE-KIf4 ${ }^{f l / f l}$-Cre-ttd mice shows expression of GAP43 (top panels) and GAPDH (bottom panels) in all samples. GAP43 band intensities were higher in EAE-KIf4 $4^{f / f l}$-Cre-ttd mice compared with control or EAE Veh-ttd mice. Corresponding box-whisker plots at the bottom of the blots shows the ImageJ-based quantitative analysis of GAP43/GAPDH expression in ON and retina among three groups. Samples derived from the same experiment and that gels/blots were processed in parallel for quantitative analysis. Statistical analysis was performed by one-way ANOVA followed by Tukey's multiple comparison test, a $p<0.05$ is considered to be statistically significant; ****p $<0.0001-0.0009$ ( $n=6$ eyes/group, experimental repeats $=3$ ).

Figure Contributions: Venu Talla acquired the data, analyzed, and generated the figure.

progress to the irreversible permanent disability with no remedy (Noseworthy, 2003; Shirani et al., 2012). MS/EAE pathogenesis involves primary axonal demyelination and axon damage which, leads to the initial loss of function that subsequently contributes to neuronal degeneration and permanent disability. Since the PERG amplitude used in the current study can detect RGC functional decline well before neuronal loss due to EAE mediated injury, it allowed us to test our pro-regenerative approach of AAVCre-GFP-mediated KO of Klf4 gene to rescue and induce axonal regeneration from non-functional injured RGCs, with the ultimate goal to revert the visual loss in these mice (Banitt et al., 2013). Our work here demonstrates that postinjury KO of Klf4 gene in RGCs of EAE mice improved the visual function by increasing the $\mathrm{ON}$ axonal regeneration and/or rescue. Expression of KLF4 in CNS neurons including RGCs of the retina is developmentally regulated, beginning at postnatal day one and is found to be inhibitory to the axon growth and regeneration (Moore et al., 2009). Increased GAP43 expression and presence of greater number of small diameter axons observed in EAE-KIff ${ }^{\text {fl/fI}}$-Cre-ttd mice ONs compared with Veh-ttd EAE mice in the current study, supports previous findings that the KO of KIf4 in vitro in adult primary CNS neurons and in vivo in ON crush models improves the axonal regeneration (Moore et al., 2009, 2011). Yet path-finding of regenerated axons in injured CNS poses a great challenge and various studies exploring the axon regenerative approaches in ON crush model showed regenerated axons going in different directions (Sun et al., 2011; Luo et al., 2013; Mehta et al., 2016), including some innervating the appropriate target, the lateral geniculate nuclei (Bei et al., 2016). Unlike in ON crush model, where the axonal injury is precisely marked and tracing the path of regenerated axon possible (Sun et al., 2011; Mehta et al., 2016), the axonal injury in EAE/MS is more diffuse and tracing the path of any regenerated axons is more difficult and can possibly be studied only by overall functional improvement. In the current study, we observed increased PERG amplitudes and preservation of RGCs on KIf4-KO in EAE mice retina that improved RGCs function which can be attributed to some of the regenerated RGC axons possibly reaching their targets.

KLF4 expression has multitude of effects on various neurologic and autoimmune diseases including EAE/MS. Depending on the type of cells and conditions under which it is expressed, it can regulate diverse cellular processes like proliferation, differentiation, development, maintenance of normal tissue homeostasis and apoptosis (McConnell and Yang, 2010; Moore et al., 2011; Ghaleb and Yang, 2017). KLF4 regulates the differentiation of interleukin (IL)-17 expressing CD4 ${ }^{+} \mathrm{T}$ cells that are known to play a critical role in MS/EAE pathogenesis. It controls the differentiation of Th17 cells by regulating the expression of 

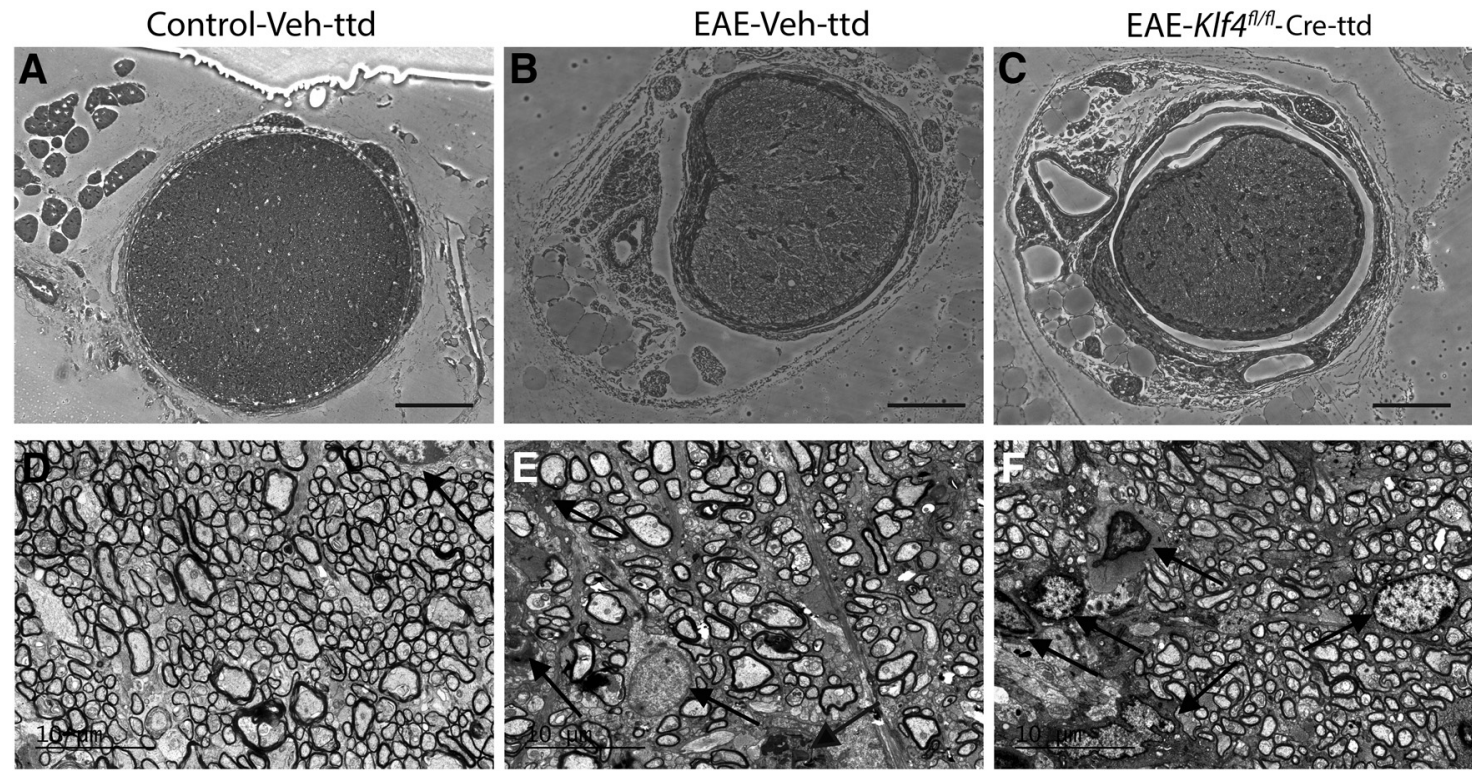

Figure 6. Histopathology and inflammation in EAE mice: $\boldsymbol{A}-\boldsymbol{C}$, Light microscopic images of the toluidine blue-stained ON sections obtained $18 \mathrm{MPS} / 9 \mathrm{MPI}$ show normal healthy axons in control-Veh-ttd mice $(\boldsymbol{A})$, whereas inflammatory infiltration and fibrosis seen in EAE-Veh-ttd $(\boldsymbol{B})$, and EAE-KIf4 ${ }^{\text {fl/fl}}$-Cre-ttd mice. $\boldsymbol{D}-\boldsymbol{F}$, Representative transmission electron micrographs show minimal to no cellular infiltration in control-Veh-ttd mice $(\boldsymbol{D})$, whereas infiltration of astroglial cells was more evident in EAE-Veh-ttd (E) and EAE-KIf4 ${ }^{f l f l}-$ Cre-ttd $(\boldsymbol{F})$ mice ONs. Scale bars: $100 \mu \mathrm{m}$ (light micrographs) and $10 \mu \mathrm{m}$ (TEM images).

Figure Contributions: Venu Talla and Rajeshwari Koilkonda acquired the images. Venu Talla generated the figure.

IL-17 (An et al., 2011). Accordingly, T cell-specific Klf4-KO mice are resistant to induction of EAE due to impaired Th17 differentiation (An et al., 2011; Hao et al., 2017). KLF4 is also involved in pro-inflammatory activation of classically activated M1 macrophages, and regulates the polarization of pro-inflammatory M1 macrophages to anti-inflammatory M2 macrophages which are found to play major role in EAE/MS pathogenesis (Feinberg et al., 2005; Liao et al., 2011). Increased expression of KLF4 in T cells, macrophages, neurons, active astroglia of EAE rat spinal cord (Ahn et al., 2015) and other auto-immune disease models including Alzheimer's (Li et al., 2017), traumatic brain injury (Cui et al., 2017) was associated with increased loss of neurons. In addition, increased expression of KLF4 under disease conditions involving ROS result in p53 mediated cell death (Cui et al., 2017; Li et al., 2017). In support of these observations, in the current study, we noted relatively higher number of live RGCs in Klf4-KO EAE mice compared with mock treated EAE mice, indicating deletion of KLF4 not only helps in axon regeneration but also appears to be protective to RGCs in EAE. However, the effect of KLF4 on neurite and axon regeneration was found to be independent of its cell survival functions (Moore et al., 2009, 2011). Klf4-KO in hippocampal neurons or embryonic RGCs or in RGCs of ON crush model showed no effect on the cell survival (Moore et al., 2009, 2011).

A new role for KLF4 in mitochondrial homeostasis and biogenesis is recently emerging (Jang and Arany, 2015). KIf4-KO in heart and kidney under various disease conditions is shown to be deleterious to mitochondrial function and homeostasis (Liao et al., 2015). In contrast, overexpression of KLF4 in embryonic and post-natal RGCs resulted in reduced mitochondrial DNA replication and mitochondrial bioenergetics (Steketee et al., 2012). In our study, we noticed higher amounts of normal sized mitochondria in Klf4-KO ON axons, whereas higher number of small sized and swollen mitochondria were found in KLF4 intact EAE ONs, indicating mitochondrial abnormality and dysfunction consistent with earlier studies. The KLF4 role in mitochondrial biogenesis and homeostasis appears to be tissue type and context dependent and incompletely understood and needs further investigation.

The limitations of the current study include the following. First, the mice were not scored on a traditional fivepoint EAE scale, as sensitization with homologous spinal cord emulsion in CFA result in a chronic model where the disease starts with milder symptoms and develop progressive axonal and neuronal degenerations. The EAE model using homologous spinal cord emulsion is well characterized and extensively published (Rao, 1981; Guy et al., 1992; Qi et al., 2006).Second, the KLF4 protein expression was evaluated at one month after Cre-GFP injection and we do not know when along the time course the KLF4 protein $\mathrm{KO}$ occurred and if it reached $>70 \%$ at later time course. Incomplete KLF4 protein KO observed in Western blottings of Cre-GFP-injected mice (i.e., 70\%) can presumably be either due to incomplete targeting of RGCs by AAV2-Cre-GFP virus or due to the contribution of KLF4 from other cell types in the retina. We did not use the contralateral eye as control, mainly to avoid the possible interference while recording PERG for RGC functional assessment that could potentially mislead the data.

In the current study, we primarily focused on ON, mainly because the ON lesion in EAE mice directly correlates to 

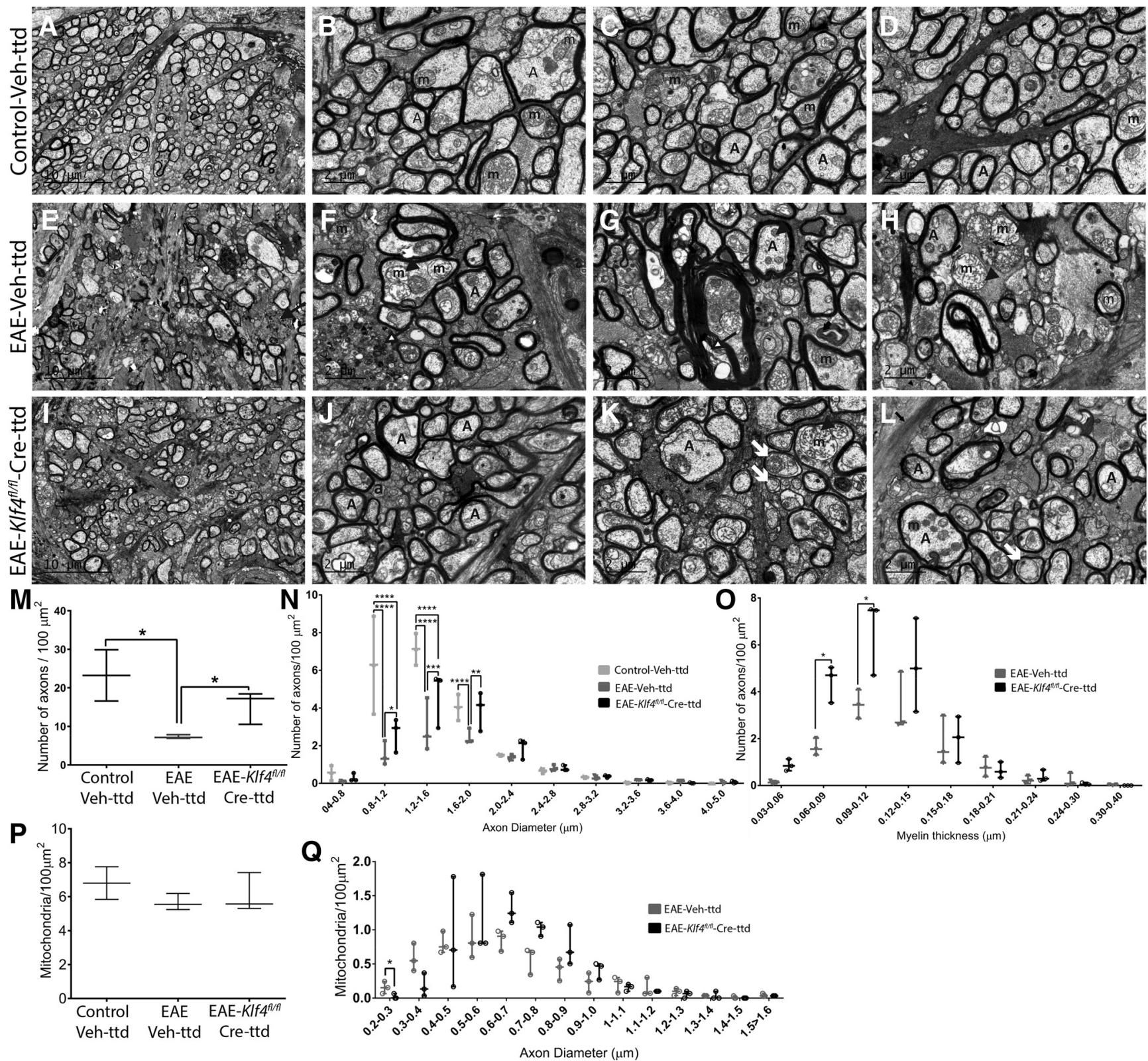

Figure 7. Axon counts, myelin, and mitochondria. Electron microscopy images of ON cross sections of $(\boldsymbol{A}-\boldsymbol{D})$ control-Veh-ttd mice shows healthy myelinated axons with normal mitochondria. $\boldsymbol{E}-\boldsymbol{H}$, EAE-Veh-ttd mice showed axonal loss and Wallerian-like degeneration (as shown by arrows in $\boldsymbol{E}, \boldsymbol{F}$ ), myelin degradation (as shown in $\mathbf{G}$ ), and axons with either smaller or swollen mitochondria (shown with arrow heads in $\mathbf{G}, \boldsymbol{H})$. I-L, EAE-KIf4 $4^{f l f f}$-Cre-ttd mice ON with low caliber axons, axons with thinner myelin (showed with arrows in $\boldsymbol{K}$ ), and normal as well as swollen mitochondria (arrowheads in $\boldsymbol{K}$ ) were evident in EAE-KIf4 $4^{f / f l}$-Cre-ttd mice. $\boldsymbol{M}$, Box and whisker plots compare axon counts among the three groups. $\boldsymbol{N}$, Box and whisker plots compare the distribution of small to high diameter axons per $100-\mu \mathrm{m}^{2}$ area in control-Veh-ttd, EAE-Veh-ttd, and EAE-KIf4 ${ }^{f / f l}$-Cre-ttd mice. $\mathbf{O}$, Box and whisker plots compare the distribution of axons with low to high myelin thickness per $100-\mu \mathrm{m}^{2}$ area in EAE-Veh-ttd versus EAE-KIf4 ${ }^{f l / f l}$-Cre-ttd mice. $\boldsymbol{P}$, Box and whisker plot compares the number of mitochondria per $100-\mu \mathrm{m}^{2}$ area in control-Veh-ttd, EAE-Veh-ttd, and EAE-KIf4 ${ }^{f / / f l}-$ Cre-ttd mice ONs. Q, Box and whisker plot compares the mitochondrial number per $100-\mu \mathrm{m}^{2}$ area with smaller to higher size in EAE-Veh-ttd versus EAE-KIf4 ${ }^{f l / f I}$ Cre-ttd mice ONs. TEM imaging and axon counting was done by individual masked for the treatment groups. Statistical analyses were performed by one-way ANOVA followed by Tukey's multiple comparison test for axon counts and mitochondrial counts. Two-way ANOVA followed by Tukey's multiple comparison test was done for axon diameters. Two-way ANOVA followed by $t$ test and statistical significance determined using the Holm-Sidak method, with $\alpha=5 \%$ and computations assume that all rows are sample from populations with the same scatter (SD) was used for myelin thickness and mitochondrial size distribution analysis; $p<0.05$ is considered to be statistically significant ( $n=3$ eyes/group, $* p=0.01-0.05, * * p=0.001-0.009, * * * p=0.0001-0.0009, * * * * p<0.0001)$. A, axons; m, mitochondria. Scale bars: $10 \mu \mathrm{m}$ (low-magnification images) and $2 \mu \mathrm{m}$ (high-magnification images).

Figure Contributions: Venu Talla and Rajeshwari Koilkonda acquired the images. Rajeshwari Koilkonda did the counting and diameters and myelin thickness measurements. Venu Talla and Rajeshwari Koilkonda analyzed the data. Venu Talla generated the figure. 
the loss of function and can be monitored in live mice using noninvasive techniques like PERG and SD-OCT (Sergott, 2005; Trip et al., 2005). Klf4-KO can be easily achieved in RGCs and ON of double floxed KIf4 mice by intravitreal injection of AAV2 Cre recombinase virus (Zhong et al., 2008), which allows to study the effect of Klf4-KO specifically in RGC neurons. By changing AAV serotype for example to AAV9 which targets brain and spinal cord, the entire CNS can be targeted in EAE/MS for further studies (Duque et al., 2009). With the advent of efficient CRISPR mediated genome editing techniques for inactivation of target gene, it is now possible to undertake studies which could translate into the clinic ( $\mathrm{Xu}$ et al., 2018). Taken together, our findings suggest that it is worth exploring the possible axonal regenerative approaches to counter permanent disability in MS/EAE.

\section{References}

Adelman G, Rane SG, Villa KF (2013) The cost burden of multiple sclerosis in the United States: a systematic review of the literature. J Med Econ 16:639-647.

Ahn M, Kim J, Park C, Jung K, Moon C, Shin T (2015) Immunohistochemical study of Krüppel-like factor 4 in the spinal cords of rats with experimental autoimmune encephalomyelitis. Acta Histochem 117:521-527.

Aktas O, Albrecht P, Hartung HP (2016) Optic neuritis as a phase 2 paradigm for neuroprotection therapies of multiple sclerosis: update on current trials and perspectives. Curr Opin Neurol 29:199-204.

An J, Golech S, Klaewsongkram J, Zhang Y, Subedi K, Huston GE, Wood WH, III, Wersto RP, Becker KG, Swain SL, Weng N (2011) Krüppel-like factor 4 (KLF4) directly regulates proliferation in thymocyte development and IL-17 expression during Th17 differentiation. FASEB J 25:3634-3645.

Balcer LJ, Miller DH, Reingold SC, Cohen JA (2015) Vision and vision-related outcome measures in multiple sclerosis. Brain 138:11-27.

Banitt MR, Ventura LM, Feuer WJ, Savatovsky E, Luna G, Shif O, Bosse B, Porciatti V (2013) Progressive loss of retinal ganglion cell function precedes structural loss by several years in glaucoma suspects. Invest Ophthalmol Vis Sci 54:2346-2352.

Bartsch U, Bandtlow CE, Schnell L, Bartsch S, Spillmann AA, Rubin BP, Hillenbrand R, Montag D, Schwab ME, Schachner M (1995) Lack of evidence that myelin-associated glycoprotein is a major inhibitor of axonal regeneration in the CNS. Neuron 15:1375-1381.

Bei F, Lee HHC, Liu X, Gunner G, Jin H, Ma L, Wang C, Hou L, Hensch TK, Frank E, Sanes JR, Chen C, Fagiolini M, He Z (2016) Restoration of visual function by enhancing conduction in regenerated axons. Cell 164:219-232.

Bjartmar C, Trapp BD (2001) Axonal and neuronal degeneration in multiple sclerosis: mechanisms and functional consequences. Curr Opin Neurol 14:271-278.

Bjartmar C, Wujek JR, Trapp BD (2003) Axonal loss in the pathology of MS: consequences for understanding the progressive phase of the disease. J Neurol Sci 206:165-171.

Cai D, Qiu J, Cao Z, McAtee M, Bregman BS, Filbin MT (2001) Neuronal cyclic AMP controls the developmental loss in ability of axons to regenerate. J Neurosci 21:4731-4739.

Chen DF, Jhaveri S, Schneider GE (1995) Intrinsic changes in developing retinal neurons result in regenerative failure of their axons. Proc Natl Acad Sci USA 92:7287-7291.

Cho KS, Yang L, Lu B, Feng MH, Huang X, Pekny M, Chen DF (2005) Re-establishing the regenerative potential of central nervous system axons in postnatal mice. J Cell Sci 118:863-872.

Cui DM, Zeng T, Ren J, Wang K, Jin Y, Zhou L, Gao L (2017) KLF4 knockdown attenuates TB1-induced neuronal damage through p53 and JAK-STAT3 signaling. CNS Neurosci Ther 23:106-118.
Duque S, Joussemet B, Riviere C, Marais T, Dubreil L, Douar AM, Fyfe J, Moullier P, Colle MA, Barkats M (2009) Intravenous administration of self-complementary AAV9 enables transgene delivery to adult motor neurons. Mol Ther 17:1187-1196.

Feinberg MW, Cao Z, Wara AK, Lebedeva MA, Senbanerjee S, Jain MK (2005) Kruppel-like factor 4 is a mediator of proinflammatory signaling in macrophages. J Biol Chem 280:38247-38258.

Frohman EM (2003) Multiple sclerosis. Med Clin North Am 87:867889, viii-ix.

Gao Y, Deng K, Hou J, Bryson JB, Barco A, Nikulina E, Spencer T, Mellado W, Kandel ER, Filbin MT (2004) Activated CREB is sufficient to overcome inhibitors in myelin and promote spinal axon regeneration in vivo. Neuron 44:609-621.

Ghaleb AM, Yang VW (2017) Krüppel-like factor 4 (KLF4): what we currently know. Gene 611:27-37.

Grinblat GA, Khan RS, Dine K, Wessel H, Brown L, Shindler KS (2018) RGC neuroprotection following optic nerve trauma mediated by intranasal delivery of amnion cell secretome. Invest Ophthalmol Vis Sci 59:2470-2477.

Guy J, Rao NA (1984) Acute and chronic experimental optic neuritis. Alteration in the blood- optic nerve barrier. Arch Ophthalmol 102:450-454.

Guy J, Mao J, Bidgood WD Jr, Mancuso A, Quisling RG (1992) Enhancement and demyelination of the intraorbital optic nerve. Fat suppression magnetic resonance imaging. Ophthalmology 99: 713-719.

Hao Z, Sheng Y, Duncan GS, Li WY, Dominguez C, Sylvester J, Su YW, Lin GHY, Snow BE, Brenner D, You-Ten A, Haight J, Inoue S, Wakeham A, Elford A, Hamilton S, Liang Y, Zúñiga-Pflücker JC, $\mathrm{He} \mathrm{HH}$, Ohashi PS, et al. (2017) K48-linked KLF4 ubiquitination by Elll ligase mule controls T-cell proliferation and cell cycle progression. Nat Commun 8:14003.

Hauswirth WW, Lewin AS, Zolotukhin S, Muzyczka N (2000) Production and purification of recombinant adeno-associated virus. Methods Enzymol 316:743-761.

Jang C, Arany Z (2015) Mitochondria Cripple without Krüppel. Trends Endocrinol Metab 26:587-589.

Khan RS, Dine K, Bauman B, Lorentsen M, Lin L, Brown H, Hanson LR, Svitak AL, Wessel H, Brown L, Shindler KS (2017) Intranasal delivery of a novel amnion cell secretome prevents neuronal damage and preserves function in a mouse multiple sclerosis model. Sci Rep 7:41768.

Khan RS, Dine K, Wessel H, Brown L, Shindler KS (2019) Effects of varying intranasal treatment regimens in ST266-mediated retinal ganglion cell neuroprotection. J Neuroophthalmol 39:191-199.

Kim JY, Koh HC, Lee JY, Chang MY, Kim YC, Chung HY, Son H, Lee YS, Studer L, McKay R, Lee SH (2003) Dopaminergic neuronal differentiation from rat embryonic neural precursors by Nurr1 overexpression. J Neurochem 85:1443-1454.

Konishi Y, Stegmüller J, Matsuda T, Bonni S, Bonni A (2004) Cdh1APC controls axonal growth and patterning in the mammalian brain. Science 303:1026-1030.

Kornek B, Storch MK, Weissert R, Wallstroem E, Stefferl A, Olsson T, Linington C, Schmidbauer M, Lassmann H (2000) Multiple sclerosis and chronic autoimmune encephalomyelitis: a comparative quantitative study of axonal injury in active, inactive, and remyelinated lesions. Am J Pathol 157:267-276.

Kuhlmann T, Lingfeld G, Bitsch A, Schuchardt J, Brück W (2002) Acute axonal damage in multiple sclerosis is most extensive in early disease stages and decreases over time. Brain 125:2202-2212.

Kutzelnigg A, Lucchinetti CF, Stadelmann C, Brück W, Rauschka H, Bergmann M, Schmidbauer M, Parisi JE, Lassmann H (2005) Cortical demyelination and diffuse white matter injury in multiple sclerosis. Brain 128:2705-2712.

Li L, Zi X, Hou D, Tu Q (2017) Krüppel-like factor 4 regulates amyloid$\beta(\mathrm{A} \beta)$-induced neuroinflammation in Alzheimer's disease. Neurosci Lett 643:131-137.

Liao X, Sharma N, Kapadia F, Zhou G, Lu Y, Hong H, Paruchuri K, Mahabeleshwar GH, Dalmas E, Venteclef N, Flask CA, Kim J, Doreian BW, Lu KQ, Kaestner KH, Hamik A, Clément K, Jain MK 
(2011) Krüppel-like factor 4 regulates macrophage polarization. J Clin Invest 121:2736-2749.

Liao X, Zhang R, Lu Y, Prosdocimo DA, Sangwung P, Zhang L, Zhou G, Anand P, Lai L, Leone TC, Fujioka H, Ye F, Rosca MG, Hoppel CL, Schulze PC, Abel ED, Stamler JS, Kelly DP, Jain MK (2015) Kruppel-like factor 4 is critical for transcriptional control of cardiac mitochondrial homeostasis. J Clin Invest 125:3461-3476.

Lovas G, Szilagyi N, Majtenyi K, Palkovits M, Komoly S (2000) Axonal changes in chronic demyelinated cervical spinal cord plaques. Brain 123:308-317.

Lu P, Wang Y, Graham L, McHale K, Gao M, Wu D, Brock J, Blesch A, Rosenzweig ES, Havton LA, Zheng B, Conner JM, Marsala M, Tuszynski MH (2012) Long-distance growth and connectivity of neural stem cells after severe spinal cord injury. Cell 150:1264-1273.

Luo X, Salgueiro Y, Beckerman SR, Lemmon VP, Tsoulfas P, Park KK (2013) Three-dimensional evaluation of retinal ganglion cell axon regeneration and pathfinding in whole mouse tissue after injury. Exp Neurol 247:653-662.

McConnell BB, Yang VW (2010) Mammalian Krüppel-like factors in health and diseases. Physiol Rev 90:1337-1381.

Mehta ST, Luo X, Park KK, Bixby JL, Lemmon VP (2016) Hyperactivated Stat3 boosts axon regeneration in the CNS. Exp Neurol 280:115-120.

Moore DL, Blackmore MG, Hu Y, Kaestner KH, Bixby JL, Lemmon VP, Goldberg JL (2009) KLF family members regulate intrinsic axon regeneration ability. Science 326:298-301.

Moore DL, Apara A, Goldberg JL (2011) Krüppel-like transcription factors in the nervous system: novel players in neurite outgrowth and axon regeneration. Mol Cell Neurosci 47:233-243.

Nagaraju M, Saleh M, Porciatti V (2007) IOP-dependent retinal ganglion cell dysfunction in glaucomatous DBA/2J mice. Invest Ophthalmol Vis Sci 48:4573-4579.

Noseworthy JH (2003) Management of multiple sclerosis: current trials and future options. Curr Opin Neurol 16:289-297.

Noseworthy JH, O'Brien PC, Petterson TM, Weis J, Stevens L, Peterson WK, Sneve D, Cross SA, Leavitt JA, Auger RG, Weinshenker BG, Dodick DW, Wingerchuk DM, Rodriguez M (2001) A randomized trial of intravenous immunoglobulin in inflammatory demyelinating optic neuritis. Neurology 56:1514-1522.

Owens T (2003) The enigma of multiple sclerosis: inflammation and neurodegeneration cause heterogeneous dysfunction and damage. Curr Opin Neurol 16:259-265.

Park KK, Liu K, Hu Y, Smith PD, Wang C, Cai B, Xu B, Connolly L, Kramvis I, Sahin M, He Z (2008) Promoting axon regeneration in the adult CNS by modulation of the PTEN/mTOR pathway. Science 322:963-966.

Petrs-Silva H, Dinculescu A, Li Q, Min SH, Chiodo V, Pang JJ, Zhong L, Zolotukhin S, Srivastava A, Lewin AS, Hauswirth WW (2009) High-efficiency transduction of the mouse retina by tyrosine-mutant AAV serotype vectors. Mol Ther 17:463-471.

Petrs-Silva H, Dinculescu A, Li Q, Deng WT, Pang JJ, Min SH, Chiodo V, Neeley AW, Govindasamy L, Bennett A, AgbandjeMcKenna M, Zhong L, Li B, Jayandharan GR, Srivastava A, Lewin AS, Hauswirth WW (2011) Novel properties of tyrosine-mutant AAV2 vectors in the mouse retina. Mol Ther 19:293-301.

Polman CH, O'Connor PW, Havrdova E, Hutchinson M, Kappos L, Miller DH, Phillips JT, Lublin FD, Giovannoni G, Wajgt A, Toal M, Lynn F, Panzara MA, Sandrock AW, AFFIRM Investigators. (2006)
A randomized, placebo-controlled trial of natalizumab for relapsing multiple sclerosis. N Engl J Med 354:899-910.

Porciatti V (2007) The mouse pattern electroretinogram. Doc Ophthalmol 115:145-153.

Porciatti V, Saleh M, Nagaraju M (2007) The pattern electroretinogram as a tool to monitor progressive retinal ganglion cell dysfunction in the DBA/2J mouse model of glaucoma. Invest Ophthalmol Vis Sci 48:745-751.

Qi X, Lewin AS, Sun L, Hauswirth WW, Guy J (2006) Mitochondrial protein nitration primes neurodegeneration in experimental autoimmune encephalomyelitis. J Biol Chem 281:31950-31962.

Rao NA (1981) Chronic experimental allergic optic neuritis. Invest Ophthalmol Vis Sci 20:159-172.

Sergott RC (2005) Optical coherence tomography: measuring in-vivo axonal survival and neuroprotection in multiple sclerosis and optic neuritis. Curr Opin Ophthalmol 16:346-350.

Shirani A, Zhao Y, Karim ME, Evans C, Kingwell E, van der Kop ML, Oger J, Gustafson P, Petkau J, Tremlett H (2012) Association between use of interferon beta and progression of disability in patients with relapsing-remitting multiple sclerosis. JAMA 308:247-256.

Steinman L, Martin R, Bernard C, Conlon P, Oksenberg JR (2002) Multiple sclerosis: deeper understanding of its pathogenesis reveals new targets for therapy. Annu Rev Neurosci 25:491-505.

Steketee MB, Moysidis SN, Weinstein JE, Kreymerman A, Silva JP, lqbal S, Goldberg JL (2012) Mitochondrial dynamics regulate growth cone motility, guidance, and neurite growth rate in perinatal retinal ganglion cells in vitro. Invest Ophthalmol Vis Sci 53:7402-7411.

Sun F, Park KK, Belin S, Wang D, Lu T, Chen G, Zhang K, Yeung C, Feng G, Yankner BA, He Z (2011) Sustained axon regeneration induced by co-deletion of PTEN and SOCS3. Nature 480:372-375.

Talman LS, Bisker ER, Sackel DJ, Long DA, Galetta KM, Ratchford JN, Lile DJ, Farrell SK, Loguidice MJ, Remington G, Conger A, Frohman TC, Jacobs DA, Markowitz CE, Cutter GR, Ying GS, Dai Y, Maguire MG, Galetta SL, Frohman EM, et al. (2010) Longitudinal study of vision and retinal nerve fiber layer thickness in multiple sclerosis. Ann Neurol 67:749-760.

Trapp BD, Peterson J, Ransohoff RM, Rudick R, Mörk S, Bö L (1998) Axonal transection in the lesions of multiple sclerosis. $\mathrm{N}$ Engl $\mathrm{J}$ Med 338:278-285.

Trip SA, Schlottmann PG, Jones SJ, Altmann DR, Garway-Heath DF, Thompson AJ, Plant GT, Miller DH (2005) Retinal nerve fiber layer axonal loss and visual dysfunction in optic neuritis. Ann Neurol 58:383-391.

Wallin MT, Culpepper WJ, Campbell JD, Nelson LM, Langer-Gould A, Marrie RA, Cutter GR, Kaye WE, Wagner L, Tremlett H, Buka SL, Dilokthornsakul P, Topol B, Chen LH, LaRocca NG; US Multiple Sclerosis Prevalence Workgroup (2019) The prevalence of MS in the United States: a population-based estimate using health claims data. Neurology 92:e1029-e1040.

Xu CL, Park KS, Tsang SH (2018) CRISPR/Cas9 genome surgery for retinal diseases. Drug Discov Today Technol 28:23-32.

Yiu G, He Z (2006) Glial inhibition of CNS axon regeneration. Nat Rev Neurosci 7:617-627.

Zhong L, Li B, Mah CS, Govindasamy L, Agbandje-McKenna M, Cooper M, Herzog RW, Zolotukhin I, Warrington KH Jr, WeigelVan Aken KA, Hobbs JA, Zolotukhin S, Muzyczka N, Srivastava A (2008) Next generation of adeno-associated virus 2 vectors: point mutations in tyrosines lead to high-efficiency transduction at lower doses. Proc Natl Acad Sci USA 105:7827-7832. 